\title{
An Investigation into Magnetic Field Management under Power Transmission Lines using Delta Configurations
}

\author{
Nagat Mohamed Kamel Abdel-Gawad*
}

Electrical Engineering Department, Shoubra Faculty of Eng., Benha University, Cairo, Egypt

\begin{abstract}
The increase of power demand has increased the need for transmitting huge amount of power over long distances. Large transmission lines configurations with high voltage and current levels generate large values of electric and magnetic fields stresses which affect the humanbeing and the nearby objects located at ground surfaces. This has in turn prompted increased activity in the documentation of calculation techniques to accurately predict field strengths in isolated conducting bodies coupled to lines of all voltages and design configurations.

Overhead transmission systems required strips of land to be designed as right-of-ways (R.O.W.). These strips of land are usually evaluated according to some aspects; the most important one is the operating effects of the energized line including magnetic and electric field effects. Therefore determination of the maximum value of the magnetic and electric field stress at ground surface is very necessary and important. It is always required to minimize the amount of land set for high voltage (or current) transmission facilities. This can be achieved by the reduction of the field stress at ground level which is also considered as the most object of efforts to minimize the field effects of such high voltage AC transmission lines.

This paper investigates the effects of the transmission line towers configurations, on the mitigation of the induced magnetic fields, around and near the transmission lines, of the $500 \mathrm{kV}$ systems. The magnetic fields of the conventional 500 $\mathrm{kV}$ normal horizontal (flat) power transmission line configuration are compared with that of the normal delta, inverted delta, compact normal delta and compact inverted delta configurations, and in turn its effects on the right of way (R.O.W) distance around the transmission line. The obtained results show that, for compact normal delta, and full compact inverted delta configurations, the resultant magnetic fields produced are lower than that produced from the conventional flat line configuration.
\end{abstract}

Keywords: Electrical Power systems -Electro-magnetic field (EMF) Management, Transmission line compaction, Effects of delta configurations, Right of way distance (ROW).

\section{INTRODUCTION}

Magnetic and electric fields are a phenomenon that is found in the area immediately surrounding all electric power transmission and distribution lines, electrical wiring in homes and such common every day appliances.

The electromagnetic environment typically consists of two components, an electric field and a magnetic field. In general for time-varying fields, these two fields are coupled but in the limit of unchanging fields, they become independent. For frequencies encountered in electric-power transmission and distribution, these two fields can be considered independent to an excellent approximation [1].

- Magnetic fields (B) arise from the motion of electric charges. A magnetic field is only produced once the device is switched on and current flows. Magnetic field lines run in circles around the conductor (i.e. produces magnetic induction on objects and induced currents inside human and animal (or any other conducting) bodies causing possible health effects and a

*Address correspondence to this author at the Electrical Engineering Department, Shoubra Faculty of Eng., Benha University, Cairo, Egypt; E-mail: ashamza55@yahoo.com

1874-8295/09 multitude of interference problems). The higher the current, the greater the strength of the magnetic field.

- $\quad$ Electric fields (E) exist whenever a (+) or (-) electrical charge is present. They exert forces on other charges within the field. Any electrical wire that is charged will produce an electric field (i.e. Electric field produces charging of bodies, discharge currents, biological effects and sparks). This field exists even when there is no current flowing. The higher the voltage, the stronger is electric field at any given distance from the wire.

Overhead electric power lines have been in operation now for many years. However, it is only in the last 50 years that health effects of their magnetic and electric fields have become a subject of interest [1].

The magnetic field produced from the transmission lines is our main concern and will be considered in this work. Designers of power lines are searching for technically and economically acceptable right-of-way (R.O.W.).

\section{MAGNETIC FIELD EFFECTIVENESS}

\subsection{Factors Affecting The Magnetic Field Level}

The magnetic field strength (B) produced from a transmission line is proportional to: load current, phase -to- phase 
spacing (i.e. line compaction), and the inverse square of the distance from the line.

Many previous works studied the effect of different parameters on the produced magnetic field (B) such as: the distance from the line, the conductor height, line shielding and transmission line configuration and compaction [2-23].

\subsubsection{The Distance from the Line}

Keeping all the parameters the same and the only variable is the distance from the line. The magnetic field dips rapidly beyond the outside conductor away from the line, at which the field from the three phases partially cancel each other at larger distances (i.e. place the line as far as necessary to reduce the field to the desired values). But it has a larger right-of-way (R.O.W) width associated with greater unused land.

\subsubsection{The Conductor Height}

Keeping all the parameters the same and the only variable is the conductor height. To reduce the magnetic field levels is by increasing the conductor height but it has the disadvantage of increased height of line tower and its cost.

\subsubsection{Line Shielding}

Line shielding in transmission line runs in parallel to the phase conductors. Line shielding is always used to mitigate the magnetic field. There are several techniques for line shielding (Passive, Active, and combined shielding). The passive shielding depends on current induced in the transmission line. This induced current generating a magnetic field. This magnetic field encounters or partially cancels the original magnetic field from phase conductor. The active shield is used to approximately cancel the dipole component of the source fields. The combining active and passive shielding techniques can produce results which are superior to either of the above mentioned technique when used alone [2].

\subsubsection{Line Configuration and Compaction}

Line compaction means that, bringing the conductors close together keeping the minimum (safe) phase-to-phase spacing constant. Compact high voltage lines allow transmission of equivalent amounts of power to conventionally designed lines of the same voltage, using less space than the conventionally designed lines [3-17].

Keeping all the parameters the same and the only variable is the phase-to- phase spacing. The magnetic field is proportional to the dimensions of the phase-to-phase spacing.

Other studies showed that, increasing the distance between phases by increasing the height of the central phase conductor above the level of the other phase conductors leads to the reduction of the peak value of the magnetic field [18].

Reducing the phase-to-phase distance, leads to the decrease of the magnetic field. This reduction between phases is limited by the electrical insulation level between phases.

a. For single circuit lines, compaction causes a great reduction to the maximum magnetic field values. This reduc- tion of magnetic field allows for lower conductor heights above the ground. This leads to transmit the same power on shorter towers. This gives a great reduction of the tower cost [18].

b. For double circuit lines, some studies showed that, the use of optimum phase arrangement causes a drastic reduction to the maximum magnetic field values for both conventional and compact lines i.e. with vertical conductor configurations arranged in ABC/CBA phase order [19, 20].

\section{EMPLOYED MAGNETIC FIELD COMPUTA- TIONAL MODEL}

For the purpose of calculating the magnetic field in this work, a three-dimension technique (3D) is used. The 3D technique is based on the Biot-Savrt law and the segment model in which the line conductor (or catenary) is simulated as connected straight line segments (or current sticks) [2427].

The Biot-Savrt law can be used to calculate the magnetic field at an arbitrary observer position (point P) associated with a current segment having an arbitrary location. The current segment is showing in Fig. (1) which is represented by a vector a. The current is assumed to be uniformly distributed along the current segment.

According to the Biot-Savart law in its general form, the magnetic field at point $(\mathrm{P})$ is given by;

$$
\begin{aligned}
\vec{B} & =\mu_{\circ} \mu_{r} \times \vec{H} \\
\vec{H} & =\frac{1}{4 \pi} \int_{v} \frac{\vec{J} \times \vec{Z}_{r r}}{[r-\vec{r}]^{2}} d v \quad \ldots .(\text { tesla }) \ldots . . .(1)
\end{aligned}
$$

where $\vec{r}$ is the position vector of the current segment (a), $r$ is the position vector of the observer point $(\mathrm{P}), \vec{J}$ is the current density in the current segment and $\vec{Z}_{r r}$ is the direction vector between the segment (a) and point (P), $\vec{H}$ is the magnetic field strength and $\vec{B}$ is the magnetic field density. Integrating the Biot-Savart law over the current segment, the

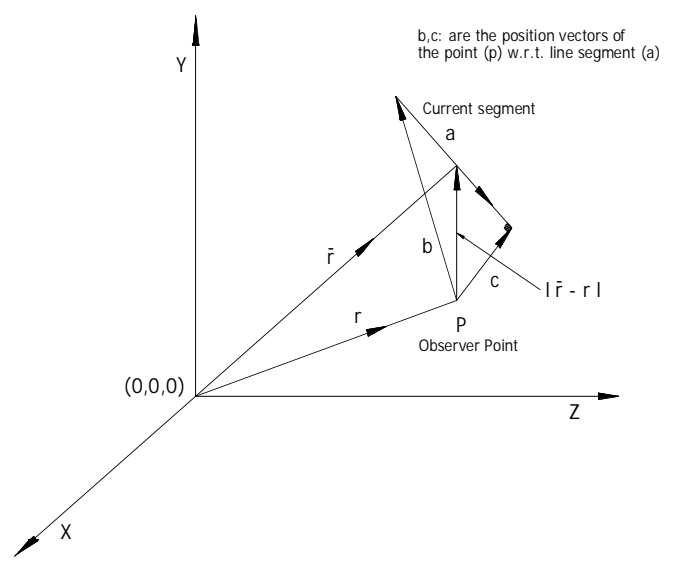

Fig. (1). A line segment representation in space. 
magnetic field at the observation point $(\mathrm{P})$ can be expressed as:

$$
\vec{H}=\frac{\vec{i}}{4 \pi} \frac{\vec{c} \times \vec{a}}{|\vec{c} \times \vec{a}|^{2}}\left\{\frac{\vec{a} \cdot \vec{c}}{|\vec{c}|}-\frac{\vec{a} \cdot \vec{b}}{|\vec{b}|}\right\} \ldots \ldots(A / m)
$$

And the magnetic flux density due to the nth current segment is given by:

$$
\vec{B}(n)=0.1\left(\vec{i} \frac{\vec{c} \times \vec{a}}{|\vec{c} \times \vec{a}|^{2}}\left\{\frac{\vec{a} \cdot \vec{c}}{|\vec{c}|}-\frac{\vec{a} \cdot \vec{b}}{|\vec{b}|}\right\}\right) \ldots \ldots \ldots(\mu T) \ldots \ldots(4)
$$

Or

$$
\vec{B}(n)=\left(B_{x}(n) \vec{i}+B_{y}(n) \vec{j}+B_{z}(n) \vec{k}\right) \quad \ldots(\mu T) \ldots(5)
$$

Where, $\mathrm{i}, \mathrm{j}$ and $\mathrm{k}$ are the unit vectors in the $\mathrm{X}, \mathrm{Y}, \mathrm{Z}$ directions, respectively. And $B_{x}(n), B_{y}(n)$ and $B_{z}(n)$ are the components of the magnetic flux densities in the $\mathrm{X}, \mathrm{Y}, \mathrm{Z}$ directions, respectively, due to the nth current segment.

For $\mathrm{N}$ current conductors, the total flux density in the coordinates $(\mathrm{x}, \mathrm{y}$, and $\mathrm{z})$ at observation point are:

$$
\begin{aligned}
\vec{b}_{x} & =\sum_{n=1}^{N} \vec{B}_{x}(n) \ldots \ldots(\mu T) \ldots \ldots .(6) \\
\vec{b}_{y} & =\sum_{n=1}^{N} \vec{B}_{y}(n) \ldots \ldots \ldots(\mu T) \ldots \ldots(7) \\
\vec{b}_{z} & =\sum_{n=1}^{N} \vec{B}_{z}(n) \ldots \ldots(\mu T) \ldots(8)
\end{aligned}
$$

The total instantaneous magnitude of the magnetic field $\left(b_{t}\right)$ at a point in space is:

$$
b_{t}=\sqrt{b_{x}^{2}}+b_{y}^{2}+b_{z}^{2} \ldots \ldots(\mu T) \ldots \ldots(9)
$$

\section{CASES UNDER STUDIES}

A comparison between magnetic fields levels at mid-span in lateral direction of a $500 \mathrm{kV}$ line for different configurations with the same line loading is carried out. The comparision between the magnetic field levels at the centeral phase of the line and the edge of the conventional right-of-way is also presented and discussed.

All magnetic field values, in the present study, are evaluated for a line current of $1 \mathrm{kA}$ (i.e. in $\mu \mathrm{T} / \mathrm{kA}$ ). Power transmission line of $500 \mathrm{kV}$ with horizontal configuration, normal delta, inverted delta, compact normal delta and compact inverted delta configurations are considered. The main information data related to the considered power lines are as shown in Figs. (2 and 3). The minimum clearance to ground at the mid-span is $12 \mathrm{~m}$, and the right-of-way (ROW) is at 25 $\mathrm{m}$ from the center line of the tower at both sides of the line. The magnetic field values are calculated at $1 \mathrm{~m}$ above ground level. No simulation is made for the tower steel

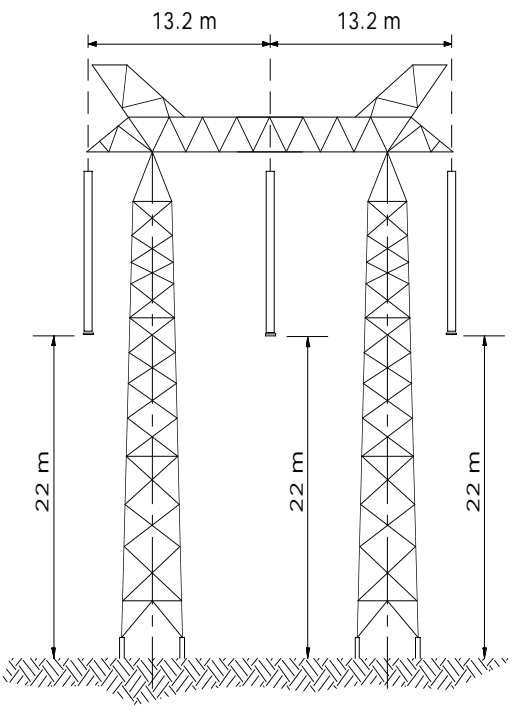

a) - Tower steel structure

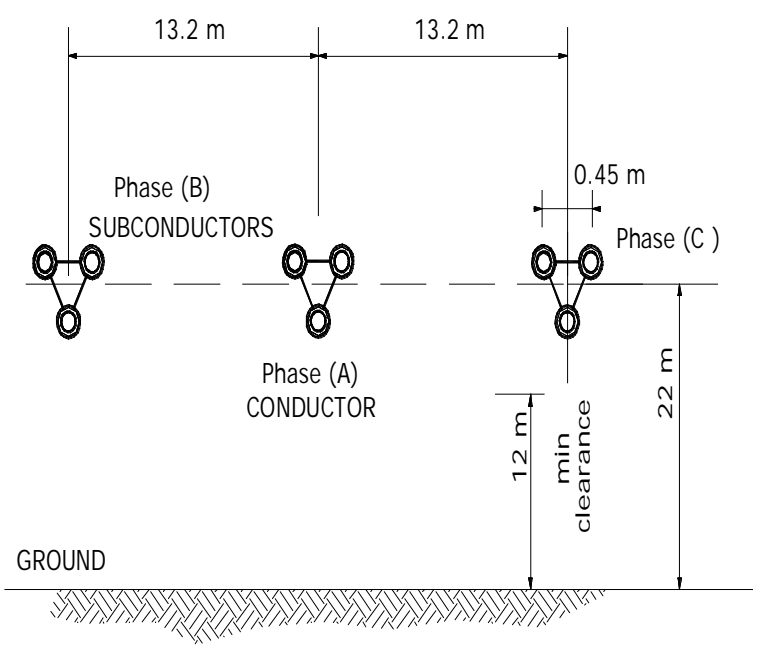

(b) T.L. conductors' arrangement

a) - Tower steel structure b) - T.L. conductors' arrangement

Fig. (2). $500 \mathrm{kV}$ power transmission line (normal Flat configurations).

structure and accordingly, some error is expected for the magnetic fields calculated near line towers.

For the purpose of the work in this paper, the following cases of studies are considered and carried out:

1- Calculation of the different magnetic field components, $B_{x}, B_{y}, B_{z}$ and the total magnetic field $B_{\text {total }}$ at the mid-span and ROW positions taking into account the effects of shifting up the suspension points of the two outer phases conductors by, $2 \mathrm{~m}$ steps, for inverted delta and compact inverted delta configurations and compare them with that, of the conventional flat configuration, of $500 \mathrm{kV}$ power transmission line. 


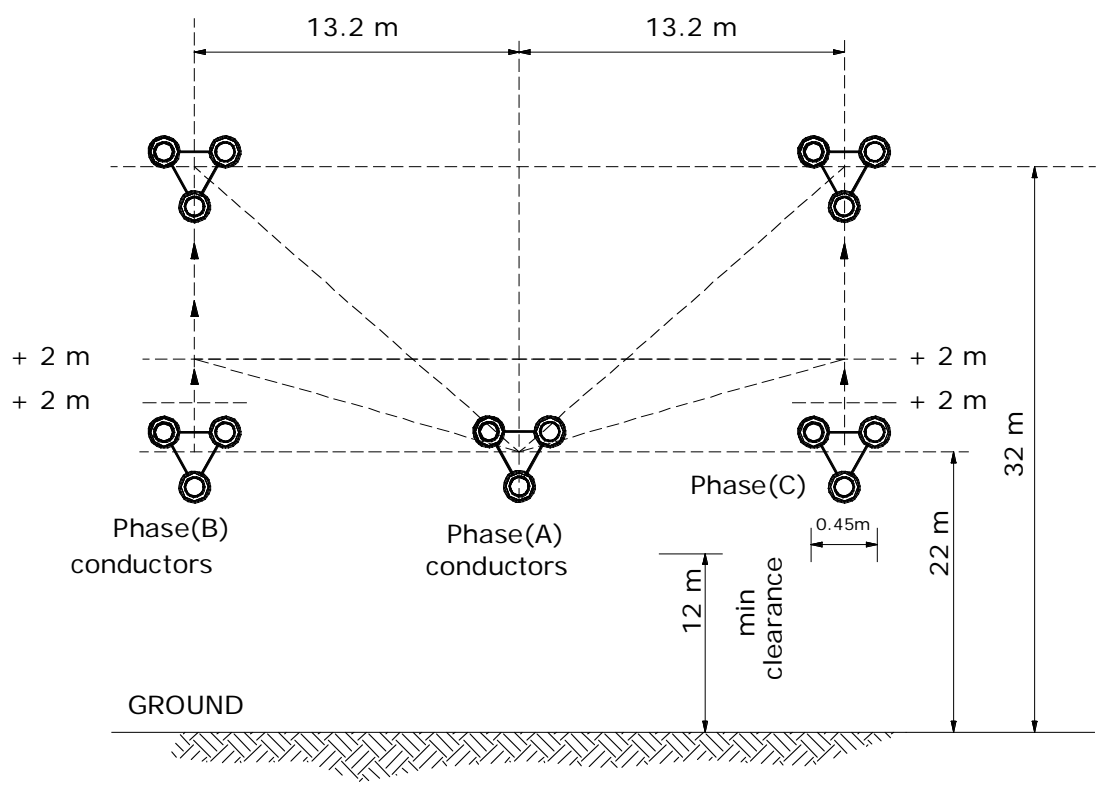

Fig. (3). $500 \mathrm{kV}$ power transmission line with Inverted Delta configurations. (T.L. conductors' arrangement, with shifting the outer phases, 2 $\mathrm{m}$, steps up).

2- Calculation of the different magnetic field components, $B_{x}, B_{y}, B_{z}$ and the total magnetic field $B_{\text {total }}$ at the mid-span and ROW positions taking into account the effects of shifting up the suspension points of the middle phase conductors, by $2 \mathrm{~m}$ steps, for normal delta and compact delta configurations and compare them with that, of the conventional flat configuration of $500 \mathrm{kV}$ power transmission line.

3- Scanning the positions of the maximum magnetic field values with respect to the central phase, for each $2 \mathrm{~m}$ shift up step, for inverted delta and compact inverted delta configurations and compare them with that of the conventional flat configuration.

4- Scanning the positions of the maximum magnetic field values with respect to the central phase, for each $2 \mathrm{~m}$ shift up step, for normal delta and compact delta configurations and compare them with that of the conventional flat configuration.

5- Scanning the positions of the maximum magnetic field values with respect to the central phase, for each $2 \mathrm{~m}$ shift up step, for full compact delta and full compact inverted delta configurations and compare them with that of the conventional flat configuration.

\subsection{Inverted Delta Configuration}

To study the effect of the conversion of the transmission line three phases conductors from, conventional flat configuration to Inverted Delta configuration, on the resultant magnetic fields around and near the transmission line. Firstly, and for accurate calculation and analysis of the produced magnetic field, calculation of the different magnetic field components $\mathrm{B}_{\mathrm{x}}, \mathrm{B}_{\mathrm{y}}, \mathrm{B}_{\mathrm{z}}$ and the total resultant magnetic field $\mathrm{B}_{\text {total }}$, is carried out at the mid-span position, with the conductors of the three phases are at suspension points of $22 \mathrm{~m}$ height from the ground, for normal flat configuration, (for the Egyptian conventional $500 \mathrm{kV}$ power transmission line) as can be seen in Fig. (2).

Secondly, the calculation of the different magnetic field components $\mathrm{B}_{\mathrm{X}}, \mathrm{B}_{\mathrm{Y}}, \mathrm{B}_{\mathrm{Z}}$ and $\mathrm{B}_{\text {total }}$ at the mid span positions, with taking the effects of shifting up the suspension points of the two outer phases conductors by, $2 \mathrm{~m}$ steps, for the reason of studying the effects of the conversion of the line conductors configuration to inverted normal delta configuration, for $500 \mathrm{kV}$ power line, is carried out as shown in Fig. (3).

Fig. (4) presents the $X$-components $\left(B_{X}\right)$ of the magnetic field lateral profiles, for different configurations, with shift up steps of $2 \mathrm{~m}$, starting from the normal flat configuration at a height of $22 \mathrm{~m}$ suspension points from the ground, till reaching $32 \mathrm{~m}$ height from the ground, for inverted delta configurations.

It can be noticed that the range of the maximum value varies and reaches a very high value compared with that, of the conventional flat configuration, at the case when shifting up the conductors of outer two phases to $32 \mathrm{~m}$ height from the ground. While the others maximum values for the other heights are small compared with that, of the flat configuration case. This is because the distances between the central phase and the outer two phases are getting larger. So, the cancellation effect is very small.

Fig. (5) presents the $\mathrm{Y}$-components $\left(\mathrm{B}_{\mathrm{Y}}\right)$ of the magnetic field lateral profiles, for the same case, for different configurations, by shift up steps, of $2 \mathrm{~m}$, starting from the flat configuration at a height of $22 \mathrm{~m}$ from the ground, till reaching $32 \mathrm{~m}$ height, for inverted delta configurations.

It can be noticed that the range of the maximum value varies and reaches a very high value, compared with that, of the conventional flat configuration, at the position of shifting up the outer phases conductors up to $32 \mathrm{~m}$ height, while the other values are still small compared to that of the flat configuration and this is again, because of the larger distances 


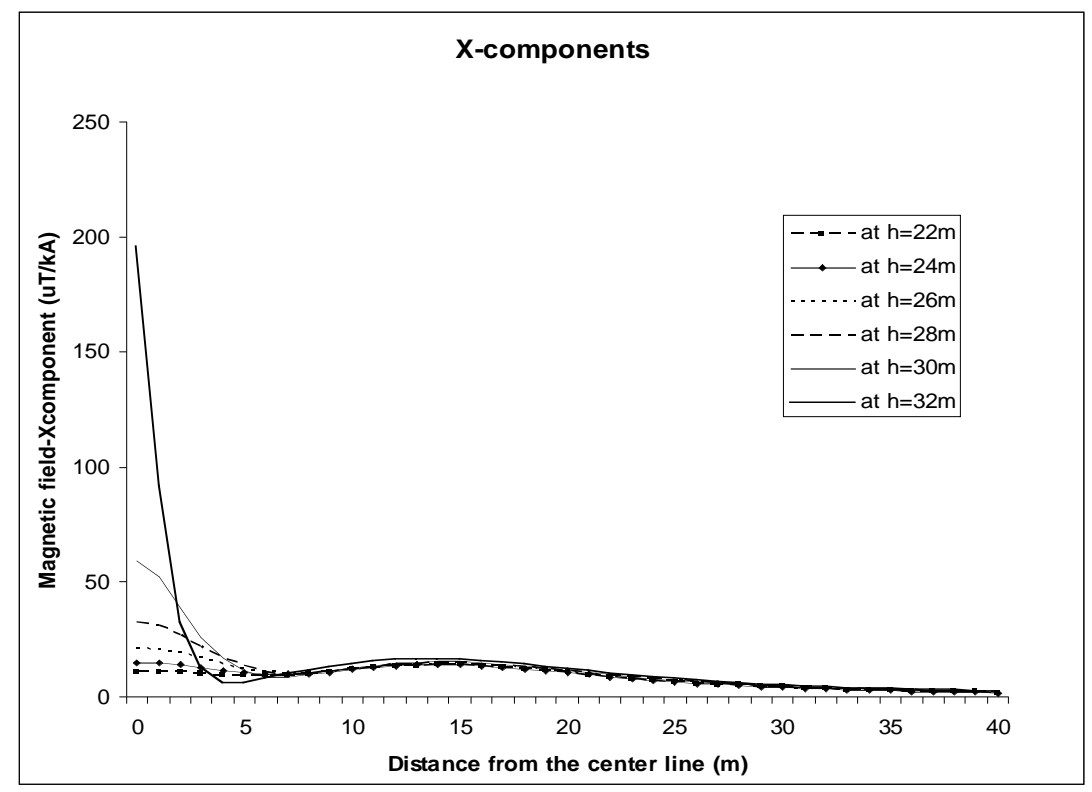

Fig. (4). The Magnetic field X-components Lateral profile at the mid-span, for inverted Delta configuration with $2 \mathrm{~m}$ shift up.

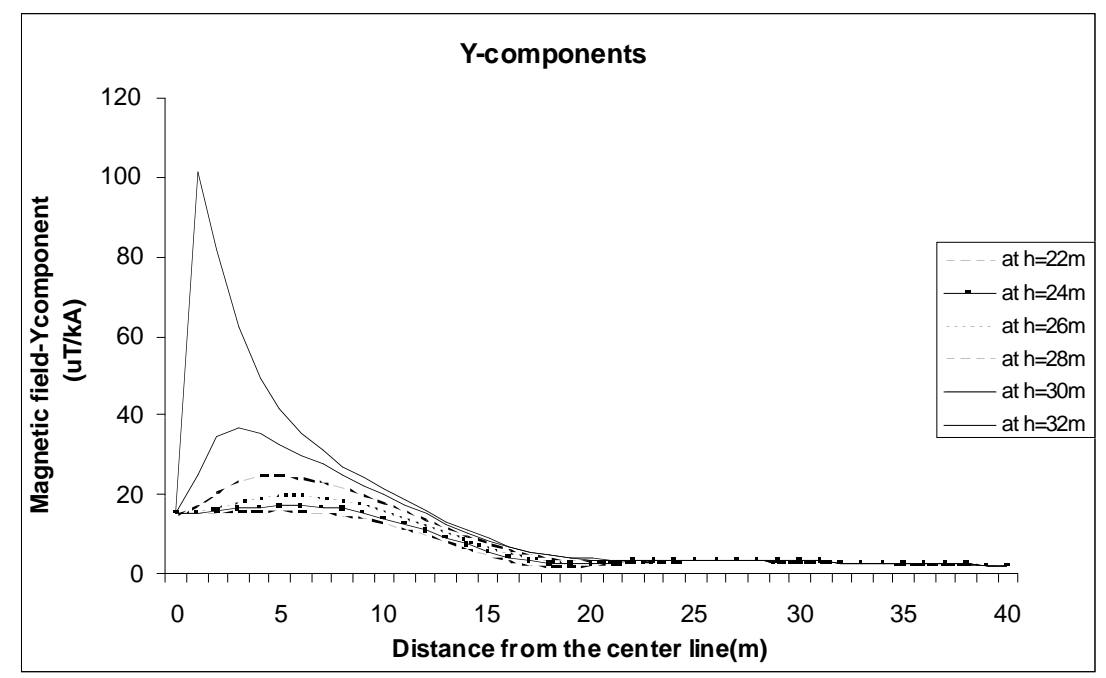

Fig. (5). The Magnetic field Y-components Lateral profile at the Mid-span, for inverted Delta configuration with $2 \mathrm{~m}$, shift up.

between the center phase and the two outer phases. So, the cancellation effect is very small. Also, it can be noticed that the value of the field Y-component is maximum in the area under the center of the T.L., as the outer phases are shifting up, as their cancellation effect on magnetic field produced by the central phase become less (very low). Meanwhile as gating more faraway from this area the magnetic field will decreases.

Also, the results for the Z-components of the magnetic field lateral profiles are obtained, for the same case of study, for different configurations. It is noticed that the maximum values of the Z-components are nearly constant because there is no changing in the Z-directions and their values are small in magnitudes compared with that of the $\mathrm{X}$ and $\mathrm{Y}$ components.
Fig. (6) presents the resultant total maximum magnetic field $\left(\mathrm{B}_{\text {total }}\right)$ lateral profiles for the different cases, with shift up steps of $2 \mathrm{~m}$, starting from the normal flat configuration, with the three phases conductors points of suspension at 22 $\mathrm{m}$ height from the ground, until reaching the high of $32 \mathrm{~m}$ from the ground, converting the line, for Inverted Delta configurations. It can be noticed that the maximum values are obtained also at $32 \mathrm{~m}$ height shift up from the ground.

Table 1 presents the different maximum magnetic field values and its position with respect to the central phased conductors for inverted delta configurations. It can be noticed that the maximum magnetic field value is obtained at, the height level of $32 \mathrm{~m}$ and $34 \mathrm{~m}$ from the ground, (i.e. with shafting the two outer phases conductors up by $10 \mathrm{~m}$ and 12 $\mathrm{m}$ from the normal flat condition position, at $22 \mathrm{~m}$ ). While 


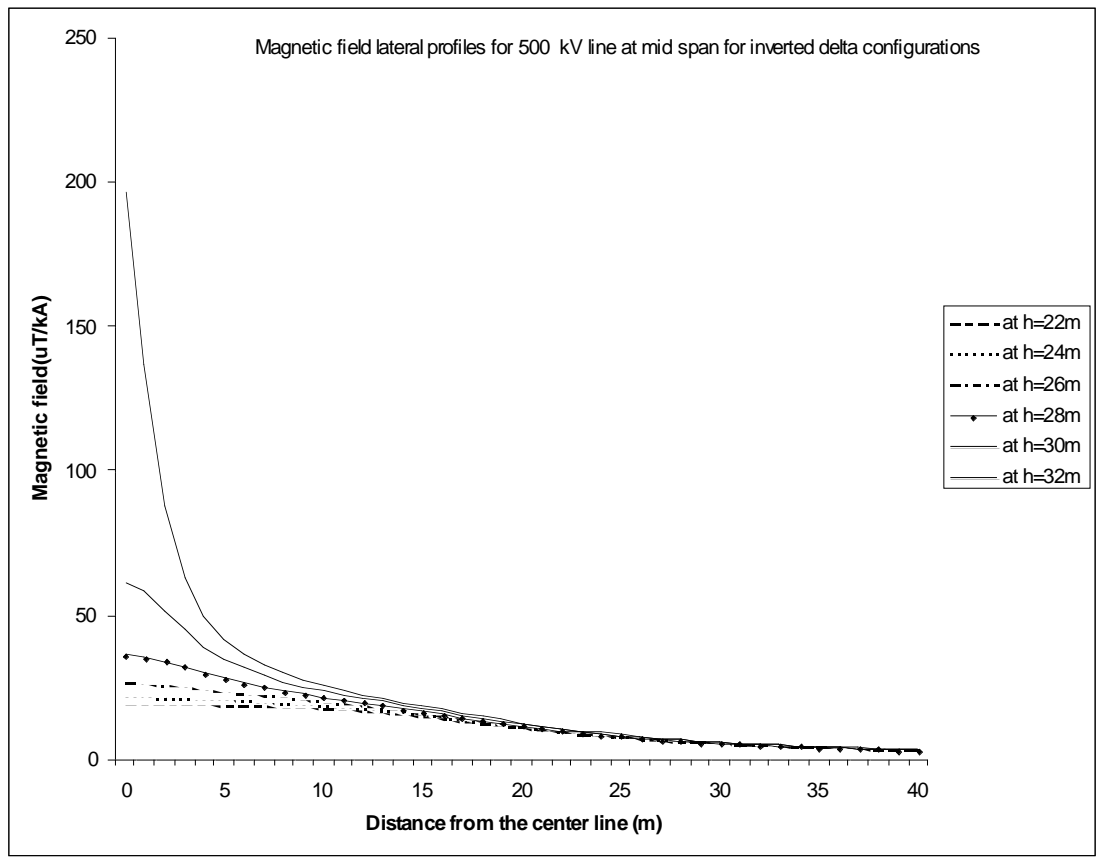

Fig. (6). The total maximum Magnetic Field Lateral profile at the Mid-span for, Inverted Delta configuration, with $2 \mathrm{~m}$ steps shift up.

Table 1. Max. Magnetic Field $\left(B_{\text {total }}\right)$ Values and its Position w.r.t Center Line for Different Heights (with 2 m steps) for Inverted Delta Configuration

\begin{tabular}{|c|c|c|}
\hline Vertical Shift up Calculation Distance (m) & Max. Field (B) Value (uT/kA) & Position w.r.t. Center Line (m) \\
\hline \hline $\begin{array}{c}\text { Reference(Base case) } \\
\text { (Flat configuration) }\end{array}$ & 18.751 & 0 \\
\hline 2 & 21.293 & 0 \\
\hline 4 & 26.057 & 0 \\
\hline 6 & 35.882 & 0 \\
\hline 8 & 61.027 & 0 \\
\hline 10 & 196.392 & 0 \\
\hline 12 & 204.962 & 0 \\
\hline 14 & 75.909 & 0 \\
\hline 16 & 50.074 & 0 \\
\hline 18 & 39.323 & 0 \\
\hline 20 & 33.543 & 0 \\
\hline
\end{tabular}

the positions of the maximum values, for all the other considered cases, produced under the central phase conductors.

Table 2 shows the maximum magnetic field values at central phase conductor (C.P.C) and at ROW positions and its percentage w.r.t. the normal conventional base case (i.e. flat configuration) for Inverted Delta configuration.

Table 2 and Fig. (7) present the maximum magnetic field $\left(B_{\text {total }}\right)$ values w.r.t the base case values, with its percentage of the value of the conventional base flat case, of $500 \mathrm{kV}$ power transmission line with inverted delta configuration.
It can be noticed that, with increasing the shift up of the conductors of two outer phases, from the ground, converting the line configuration from, conventional flat to inverted delta configuration, the higher maximum magnetic field $\left(\mathrm{B}_{\text {total }}\right)$ values are obtained, at both of, under the central phase conductor (C.P.C) and at the ROW positions. The increase of the resultant magnetic fields reaches a value of around 8.15 $\%$ at ROW, when the outer phases are shifted up by $8 \mathrm{~m}$; this is because the distances between the central phase and the outer two phases become larger. So, the cancellation effect is very small. 
Table 2. The Maximum Magnetic Field ( $\left.B_{\text {total }}\right)$ Values at C.P.C and at ROW for Inverted Delta Configuration w.r.t. Base Case (Flat Configuration)

\begin{tabular}{|c|c|c|c|c|c|c|}
\hline \multirow{2}{*}{ Case of Study } & \multicolumn{4}{|c|}{ Magnetic Field Values } \\
\cline { 2 - 6 } & \multicolumn{2}{|c|}{ Max. at C.P.C } & \multicolumn{2}{c|}{ Max. Values } & \multicolumn{2}{c|}{ Max. at ROW } \\
\cline { 2 - 7 } & uT/kA & uT/kA & 18.751 & 100 & 4.341 \\
\hline \hline Flat (Base Case) & 18.751 & 100 & 21.293 & 113.557 & 4.379 \\
\hline 2 m shift up & 21.293 & 113.557 & 26.057 & 138.963 & 4.451 \\
\hline 4 m up & 26.057 & 138.963 & 35.882 & 191.361 & 4.557 & 100.875 \\
\hline 6 m up & 35.882 & 191.361 & 61.027 & 325.460 & 4.695 & 108.155 \\
\hline 8 m up & 61.027 & 325.460 & 196.362 & 1047.208 & 4.859 \\
\hline $10 \mathrm{~m}$ up & 196.362 & 1047.208 & & & 111.933 \\
\hline
\end{tabular}

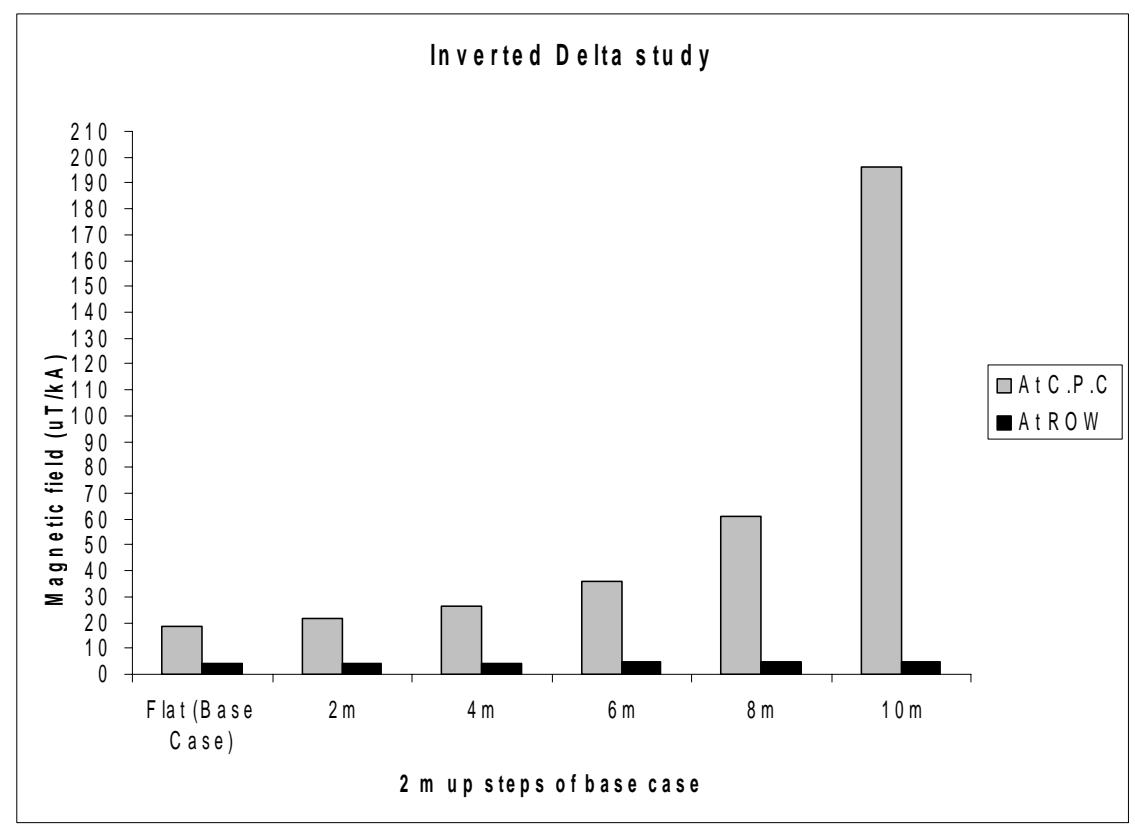

Fig. (7). The maximum magnetic field $\left(\mathrm{B}_{\text {total }}\right)$ values at C.P.C and at ROW for, Inverted Delta configurations, w.r.t. the base case (normal flat configuration).

\subsection{Normal Delta Configuration}

To study the effect of the conversion of the transmission line three phases conductors' configuration, from normal conventional flat configuration to normal Delta configuration, on the resultant and produced magnetic fields around and near the transmission line, many cases of study are carried. In these cases of the study, calculation of the different magnetic field components $\mathrm{B}_{\mathrm{X}}, \mathrm{B}_{\mathrm{Y}}, \mathrm{B}_{\mathrm{Z}}$ and $\mathrm{B}_{\text {total }}$, at the midspan position, are carried out, taking the effects of shifting up the suspension point of the middle central phase conductors in, $2 \mathrm{~m}$ steps, up to the height of $32 \mathrm{~m}$ from the ground, starting from the case of normal flat configuration with $22 \mathrm{~m}$ suspension points height, for all three phases, from the ground, converting for normal delta configuration, with minimum clearance of $12 \mathrm{~m}$ from the ground, for $500 \mathrm{kV}$ power transmission line as shown in Fig. (8).
Fig. (9) presents the total magnetic field $\left(\mathrm{B}_{\text {total }}\right)$ lateral profiles, for the different cases of shift up steps, of $2 \mathrm{~m}$, starting from the normal conventional flat horizontal configuration till reaching $32 \mathrm{~m}$ height from the ground, for normal delta configurations.

It can be noticed that the range of the maximum (B) values varies and the higher value is obtained at the conventional flat configuration. Any shift up, of the central phase conductors increases the effects of the field cancellation factors and reduces the obtained maximum field values.

Table 3 presents the different maximum Magnetic field $\left(\mathrm{B}_{\text {total }}\right)$ values and it position with respect to the central phased conductors (C.P.C.) for the different considered and studied cases of (normal delta) configurations. 


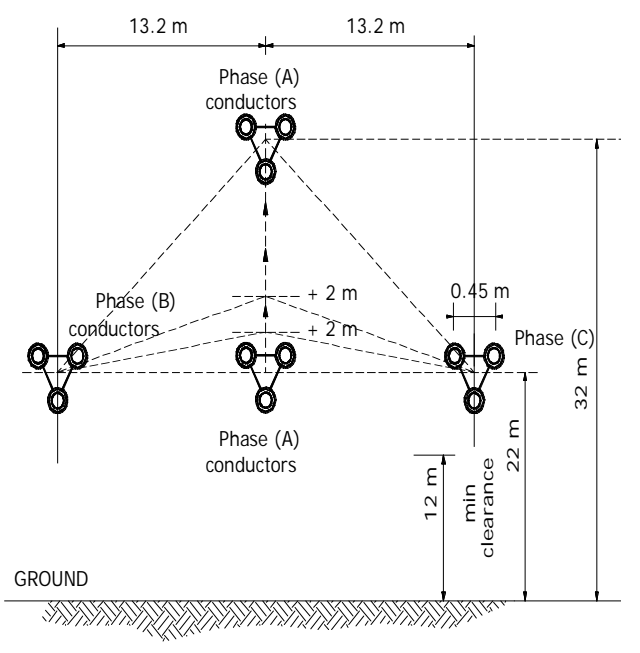

Fig. (8). $500 \mathrm{kV}$ power transmission line, normal Delta, configurations. (T.L. conductors' arrangement, with the central phase, $2 \mathrm{~m}$, steps shifting up).

It can be noticed that the maximum magnetic field $\left(\mathrm{B}_{\text {total }}\right)$ value is obtained at the case of normal conventional flat configuration, directly under the central line. There is a reduction of the magnetic field produced, as the central phase is shifted up, with the positions of the maximum value, for all the considered cases, is shifted away from under the central phase conductor of the power transmission line (for a distance of $2 \mathrm{~m}$ to a maximum distance of $9 \mathrm{~m}$ ).

Table 4 and Fig. (10) present the maximum magnetic field $\left(\mathrm{B}_{\text {total }}\right)$ values, for normal delta configurations, and its percentage w.r.t. the base case (conventional flat horizontal configuration) value of the $500 \mathrm{kV}$ power transmission line.

It can be noticed that, with increasing the shift up of the central phase conductors from the ground, the lower maximum magnetic field $\left(\mathrm{B}_{\text {total }}\right)$ values, are obtained at central phase conductor (C.P.C) position. This reduction reaches a value of around $16.2 \%$, by shifting the central phase by $8 \mathrm{~m}$ up. On the other hand, it causes higher magnetic field values at the ROW position as the central phase conductor is getting higher, with $2.6 \%$ for the same case.

\subsection{Compact Delta Configurations Cases and Results}

Line compaction means that, bringing the conductors of the three phase line close together, with keeping the minimum safe phase-to-phase spacing constant between phases. High voltage compact lines allow transmission of the same equivalent amounts of electrical power by the conventionally designed lines of the same voltage, while taking up and occupying less space than the conventionally designed lines. A conventional $500 \mathrm{kV}$ power transmission line is considered

Table 3. Max. Magnetic Field Values and its Position w.r.t. Center Line for Different Heights (with 2 m Steps, Shift Up) for Normal Delta

\begin{tabular}{|c|c|c|}
\hline $\begin{array}{c}\text { ConfigurationVertical } \\
\text { Shift Up Calculation } \\
\text { Distance (m) }\end{array}$ & $\begin{array}{c}\text { Max. Field } \\
\text { Value (uT/kA) }\end{array}$ & $\begin{array}{c}\text { Position w.r.t. } \\
\text { Center Line (m) }\end{array}$ \\
\hline \hline $\begin{array}{c}\text { Reference (Base case) } \\
\text { (Flat configuration) }\end{array}$ & 18.751 & 2 \\
\hline 2 & 17.315 & 6 \\
\hline 4 & 16.616 & 7 \\
\hline 6 & 16.247 & 8 \\
\hline 8 & 16.052 & 8 \\
\hline 10 & 15.96 & 8 \\
\hline 12 & 15.927 & 8 \\
\hline 14 & 15.932 & 9 \\
\hline 16 & 15.97 & 9 \\
\hline 18 & 16.061 & 9 \\
\hline 20 & 16.081 & \\
\hline
\end{tabular}

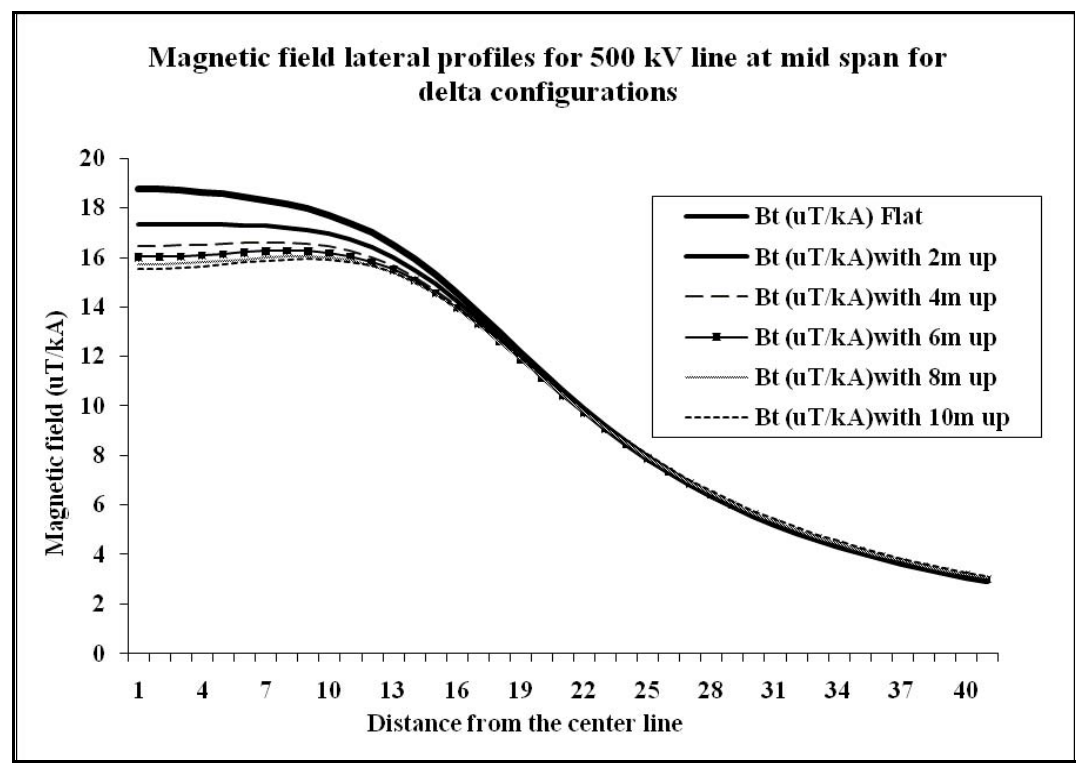

Fig. (9). The Magnetic field Lateral profiles at the Mid-span position for normal Delta configuration, with $2 \mathrm{~m}$, steps shift up. 
Table 4. The Maximum Magnetic Field Values at C.P.C and at ROW, for Normal Delta Configuration and Its Percentage w.r.t. Base Case

\begin{tabular}{|c|c|c|c|c|c|c|}
\hline \multirow{3}{*}{ Case of Study } & \multicolumn{6}{|c|}{ Magnetic Field Values } \\
\hline & \multicolumn{2}{|c|}{ Max. at C.P.C } & \multicolumn{2}{|c|}{ Max. Values } & \multicolumn{2}{|c|}{ Max. at ROW } \\
\hline & uT/kA & $\%$ & uT/kA & $\%$ & $\mathbf{u T} / \mathbf{k A}$ & $\%$ \\
\hline Flat (Base Case) & 18.751 & 100 & 18.751 & 100 & 4.341 & 100 \\
\hline $2 \mathrm{~m}$ shift up & 17.314 & 92.336 & 17.315 & 92.342 & 4.329 & 99.724 \\
\hline $8 \mathrm{~m} \mathrm{up}$ & 15.710 & 83.782 & 16.052 & 85.606 & 4.454 & 102.603 \\
\hline $10 \mathrm{~m}$ up & 15.548 & 82.918 & 15.960 & 85.116 & 4.534 & 104.446 \\
\hline
\end{tabular}

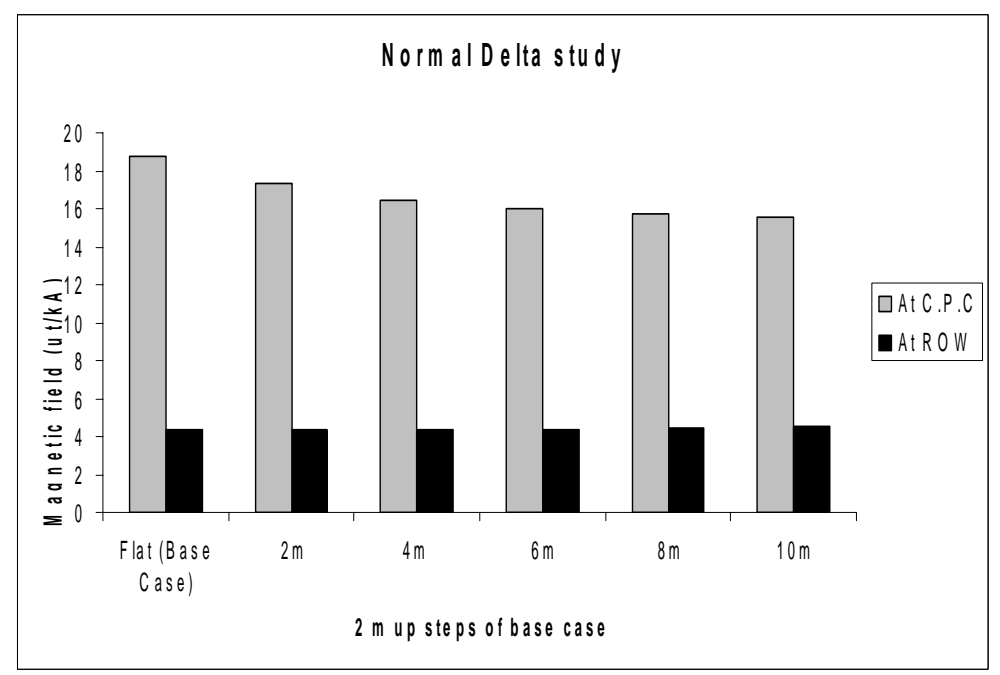

Fig. (10). The maximum magnetic field $\left(B_{\text {total }}\right)$ values, at C.P.C. and at ROW for different, normal delta configurations, compared with the Base Case.

for the purpose of magnetic field comparison with compact lines.

This section presents the results obtained for normal conventional flat configuration of $500 \mathrm{kV}$ power transmission line (Reference base case) compared with that of the line with compact normal delta and compact inverted delta configurations (i.e. with keeping the distances between the central phase and the two outer phases, constant, at the safe distance of $13.2 \mathrm{~m}$ ), and with minimum clearance of $12 \mathrm{~m}$ from the ground.

\subsubsection{Compact Inverted Delta Configuration}

Fig. (11) represents the simulation of the different cases of the study of the compact inverted delta configurations of the transmission line. The figure shows the conductors arrangement, with the outer phases move on a $13.2 \mathrm{~m}$ circle, to become closer to each other, while shifting up with, $2 \mathrm{~m}$ steps, with keeping a safe constant spacing of $13.2 \mathrm{~m}$ between the central phase and the outer phases.

The following results are obtained for the case of compact Inverted Delta, with keeping the suspension point of the central phase conductors at $22 \mathrm{~m}$ height from the ground, while shifting the outer two phases conductors up, with $2 \mathrm{~m}$ steps, on a circle curve (with the central phase is its center), as shown and simulated in Fig. (11). This is, to keep its distances from the central phase constant at $13.2 \mathrm{~m}$, while the outer phases become closer to each other and the distance between them becomes less, but not less than the safe distance. So the tower and the line conductors' configuration become more compact with the saving of the land strip along the transmission line extension.

Fig. (12) shows the results obtained for the different considered cases. The figure presents the magnetic field $\left(\mathrm{B}_{\text {total }}\right)$ values of $500 \mathrm{kV}$ power transmission line with compact inverted delta configuration and shifting up the outer phases conductors with $2 \mathrm{~m}$ steps, with keeping them moving on circle curve (at a constant safe distance of $13.2 \mathrm{~m}$ from the central phase). With the central phase is suspended at a constant height of $22 \mathrm{~m}$ and with minimum clearance of $12 \mathrm{~m}$ from the ground.

It can be noted that, the higher the outer phases conductors from the ground, the higher the magnetic field $\left(B_{\text {total }}\right)$ values are obtained, and this is because of the central phase conductor is still alone close to ground and the field cancel- 


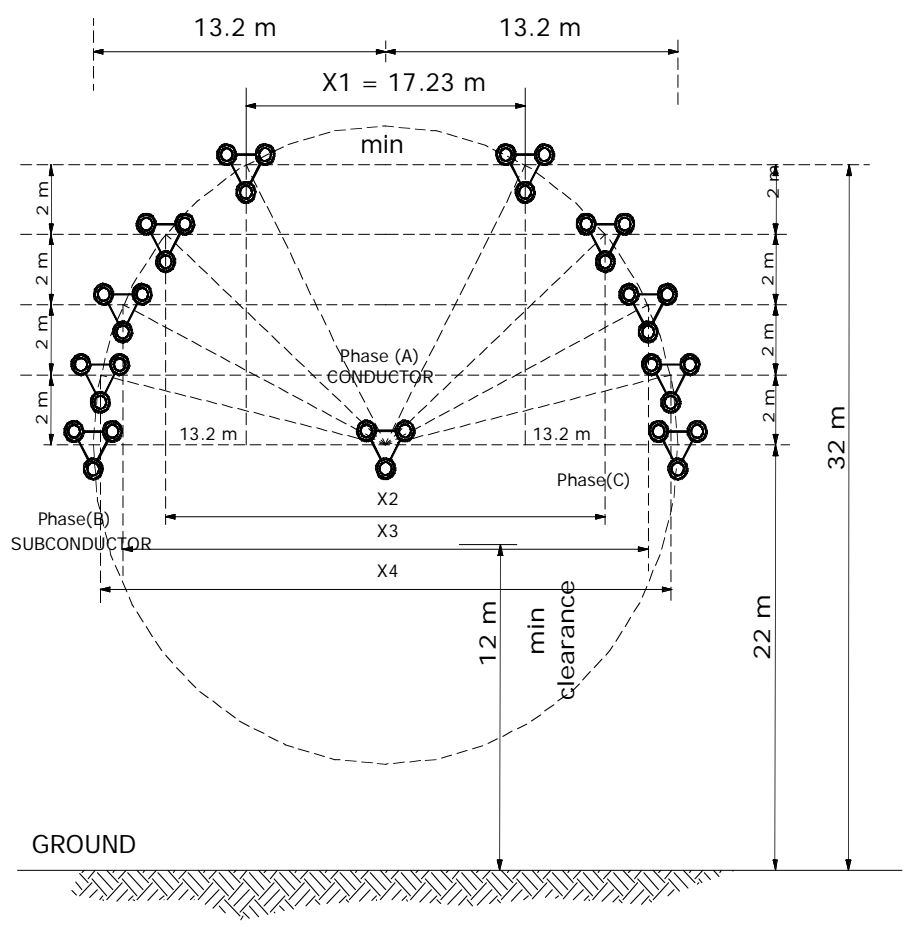

Fig. (11). $500 \mathrm{kV}$ power transmission line with compact Inverted Delta configurations (T.L. conductors arrangement, with the outer phases, move on a $13.2 \mathrm{~m}$ circle, with $2 \mathrm{~m}$, Step shift up (and constant distance between central phase and outer phases).

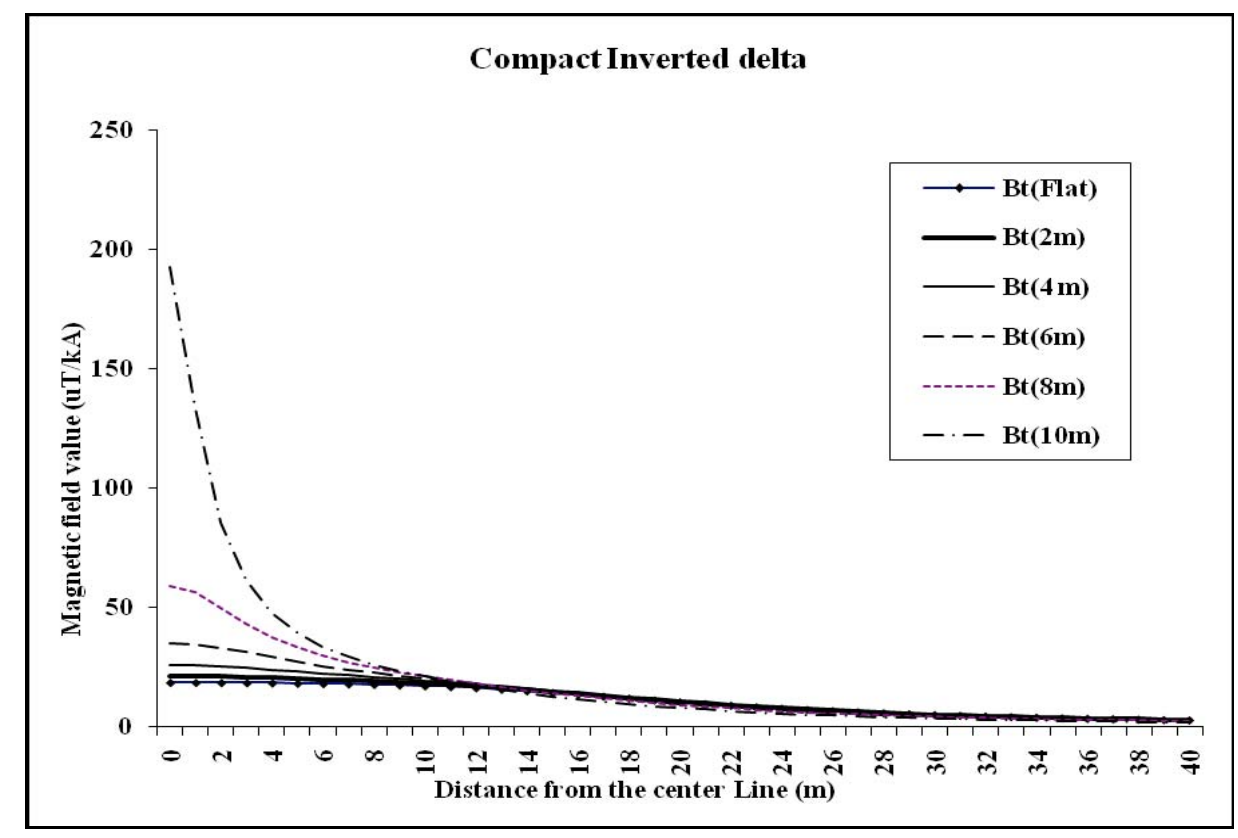

Fig. (12). Magnetic field values (uT/kA) for $500 \mathrm{kV}$ Power line with Compact Inverted delta and shifting up the outer phases conductors with $2 \mathrm{~m}$ steps ( on circle curve).

lation factor effect of the two outer phases conductors becomes small, so higher magnetic field values are obtained.

Table 5 and Fig. (13) present the obtained maximum magnetic field $\left(\mathrm{B}_{\text {total }}\right)$ values at, the central phase conductor (C P C) and at the ROW positions, for the compact inverted delta configuration, and its percentage w.r.t. the conventional base case of (the flat horizontal configuration) value, for the $500 \mathrm{kV}$ power transmission line.
It can be seen that, with increasing the shift up of the conductors of the two outer phases, higher maximum magnetic field values are obtained at the central phase position. On the other hand there are lower values of the magnetic field obtained at the ROW, as the outer phases are shifting up. The reduction reaches a value of around $15.7 \%$, when the outer phases are shifted up by $8 \mathrm{~m}$ height, from the nor- 


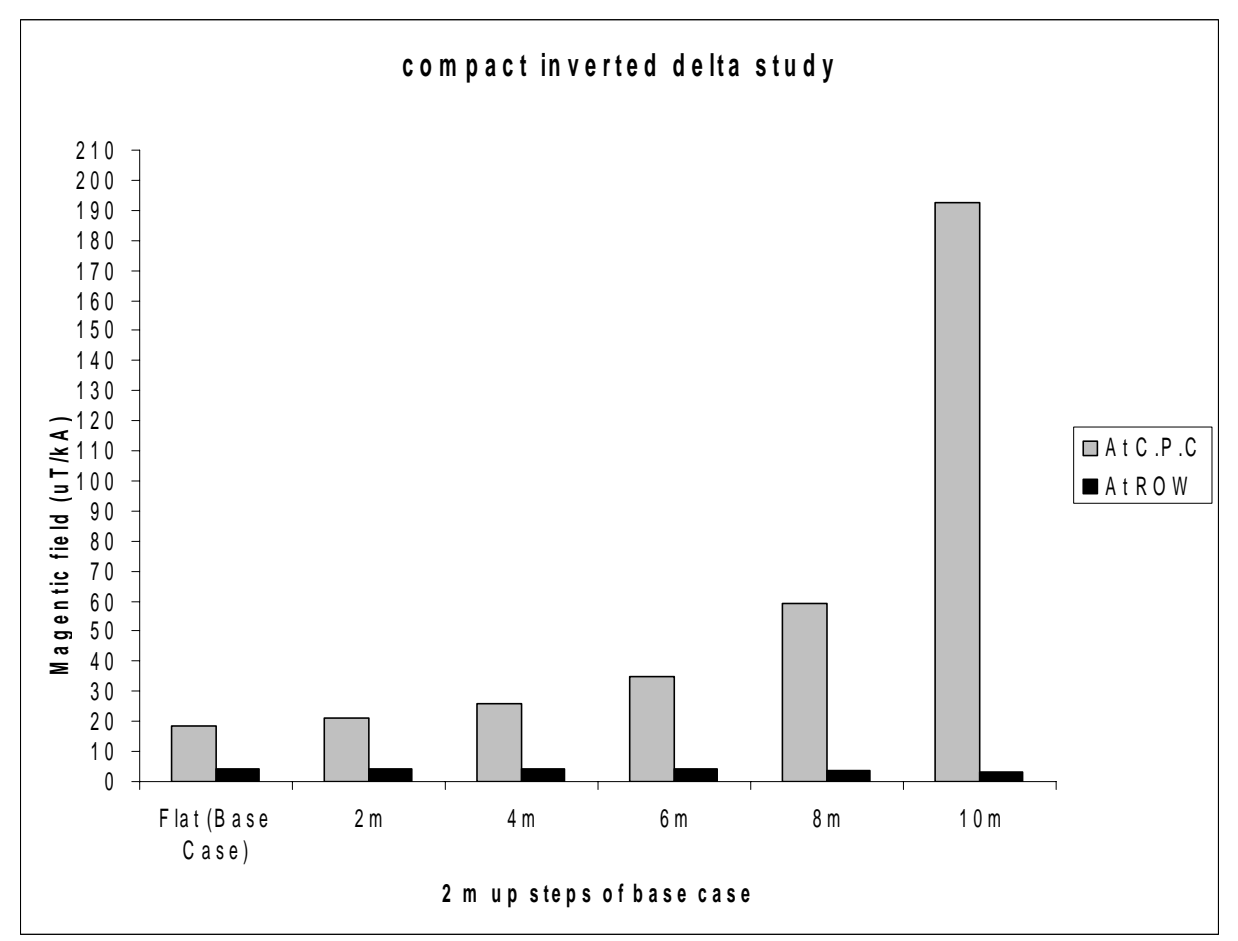

Fig. (13). The maximum magnetic field values for (compact inverted delta) at central phase conductor (C.P.C) and at ROW w.r.t. the Base Case (Flat horizontal configuration).

Table 5. The Maximum Magnetic Field Values for (Compact Inverted Delta) at Central Phase Conductor (C.P.C) and at ROW w.r.t. the Base Case (Flat Horizontal Configuration)

\begin{tabular}{|c|c|c|c|c|c|c|}
\hline \multirow{2}{*}{ Case of Study } & \multicolumn{6}{|c|}{ Magnetic Field Values } \\
\hline & $\mathbf{u T} / \mathbf{k A}$ & $\%$ & $\mathbf{u T} / \mathbf{k A}$ & $\%$ & $\mathbf{u T} / \mathbf{k A}$ & $\%$ \\
\hline Flat (Base Case) & 18.751 & 100 & 18.751 & 100 & 4.341 & 100 \\
\hline $2 \mathrm{~m}$ shift up & 21.246 & 113.306 & 21.246 & 113.306 & 4.314 & 99.378 \\
\hline $6 \mathrm{~m}$ up & 35.059 & 186.971 & 35.059 & 186.971 & 3.976 & 91.592 \\
\hline $8 \mathrm{~m}$ up & 59.118 & 315.279 & 59.118 & 315.279 & 3.660 & 84.312 \\
\hline $10 \mathrm{~m} \mathrm{up}$ & 192.582 & 1027.049 & 192.582 & 1027.049 & 3.239 & 74.614 \\
\hline
\end{tabular}

mal flat conventional configuration, of $22 \mathrm{~m}$ height and with minimum clearance of $12 \mathrm{~m}$ from the ground.

\subsubsection{Compact Normal Delta Configuration}

Fig. (14) represents the simulation of the different cases of the study of the compact normal delta configurations of the transmission line. With shifting the central phase up on a vertical line, by $2 \mathrm{~m}$ steps, and moving the outer two phases on a horizontal line, closer to each other, in steps and at a 22 $m$ suspension points from the ground, with minimum clearance of $12 \mathrm{~m}$., and keeping the distance between the conductors of the central phase and the outer phases at a constant safe spacing of $13.2 \mathrm{~m}$.
The following results are obtained for the case under study of the normal Compact Delta, as shown in Fig. (14).

The results obtained for the different considered cases of the study are shown in Fig. (15).

It can be noted that as the higher the central phase conductors the lower are the magnetic field values. This is because of, with shifting up the central phase conductors on a vertical line, with moving the two outer phase conductors to become closer to each other, and at a constant distance from the central phase, which increases the effects of the field cancellation factor. So, the lower magnetic field values are obtained. 


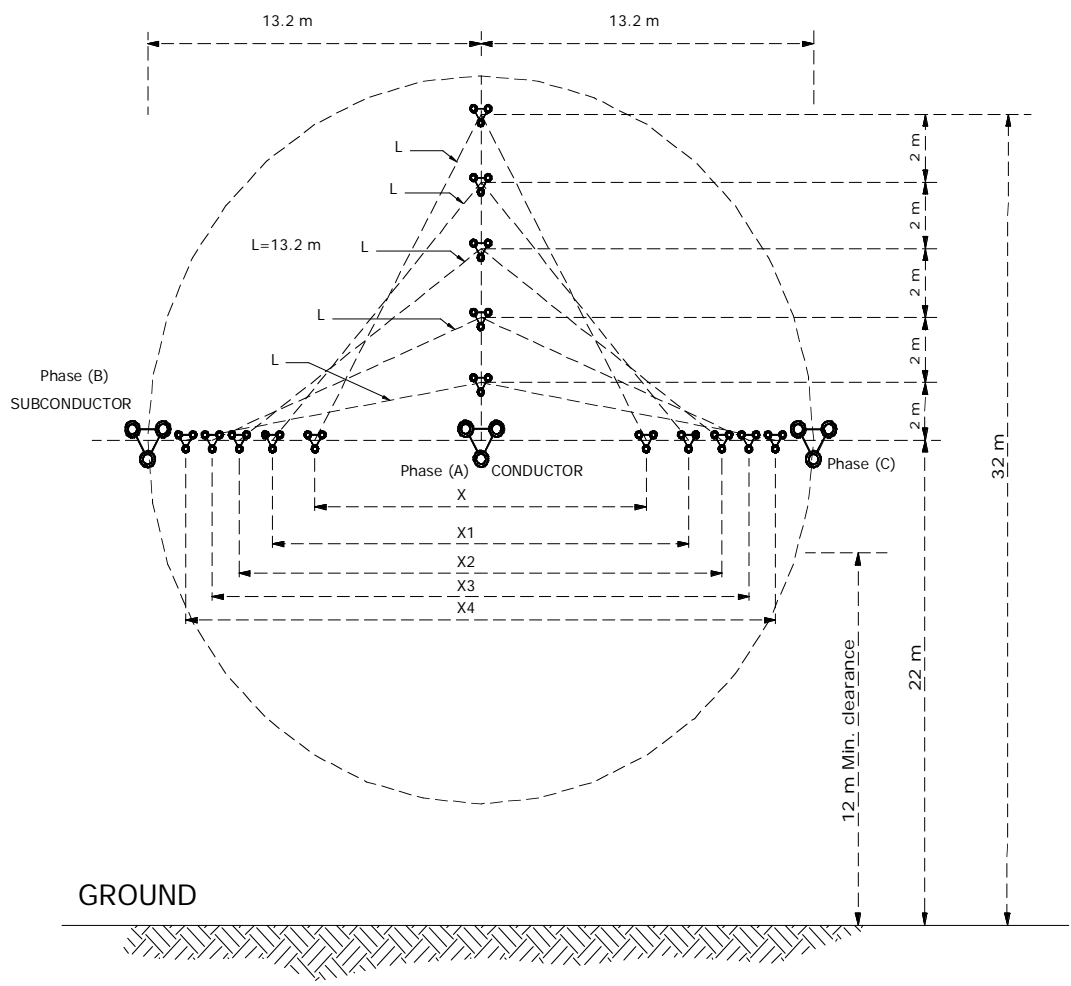

Fig. (14). $500 \mathrm{kV}$ power transmission line, normal compact Delta configurations. (T.L. conductors arrangement, with the central phase is shifting up, on a central line, by $2 \mathrm{~m}$ steps up (and the outer phases moving on a horizontal line at $22 \mathrm{~m}$ ).

Table 6. The Maximum Magnetic Field (B) Values at C.P.C and at ROW for Compact Normal Delta and its Percentage Values w.r.t. Base Case

\begin{tabular}{|c|c|c|c|c|c|c|}
\hline \multirow{2}{*}{ Case of Study } & \multicolumn{6}{|c|}{ Magnetic Field Values } \\
\hline & $\mathbf{u T} / \mathbf{k A}$ & $\%$ & $\mathbf{u T} / \mathbf{k A}$ & $\%$ & $\mathbf{u T} / \mathbf{k A}$ & $\%$ \\
\hline Flat (Base Case) & 18.751 & 100 & 18.751 & 100 & 4.341 & 100 \\
\hline $2 \mathrm{~m}$ shift up & 17.296 & 92.240 & 17.296 & 92.240 & 4.265 & 98.249 \\
\hline $6 \mathrm{~m}$ up & 16.025 & 85.462 & 16.025 & 85.462 & 3.829 & 88.206 \\
\hline $8 \mathrm{~m}$ up & 15.692 & 83.686 & 15.692 & 83.686 & 3.461 & 79.728 \\
\hline $10 \mathrm{~m} \mathrm{up}$ & 15.326 & 81.734 & 15.326 & 81.734 & 2.978 & 68.602 \\
\hline
\end{tabular}

Table 6 and Fig. (16) present the maximum magnetic field $\left(\mathrm{B}_{\text {total }}\right)$ values and its percentage values w.r.t. the base case (flat horizontal configuration), values of $500 \mathrm{kV}$ power line obtained with compact normal delta configuration.

It can be noticed that increasing the shift up of the central phase conductors from the ground, lower maximum magnetic field values are obtained, at both of the central phase conductor (C.P.C) and at the ROW positions, with a reduction of $16.3 \%$ and $20.3 \%$, respectively for $8 \mathrm{~m}$ shift up case. This is because of the effect of the cancellation factor.

\subsubsection{The Cases of Full Compaction}

The full compaction means, keeping the spacing between all three phases, constant at the safe distance of $13.2 \mathrm{~m}$. Fig.
(17) presents the results obtained for the two full compaction cases of compact normal delta and compact inverted delta transmission line configurations. These results are obtained with keeping the spacing between all three phases, constant at the safe distance of $13.2 \mathrm{~m}$. These obtained results are compared with those obtained for the case of normal conventional flat configuration of the $500 \mathrm{kV}$ power transmission line.

The obtained results show that, the magnetic field values obtained for the case of full compact inverted delta configuration (Inv.Delta) is lower than those obtained for the case of the conventional configuration up to the ROW distance (at $25 \mathrm{~m}$ ) from the center line of the transmission line. Then the produced magnetic field values of the (Inv.Delta) become 


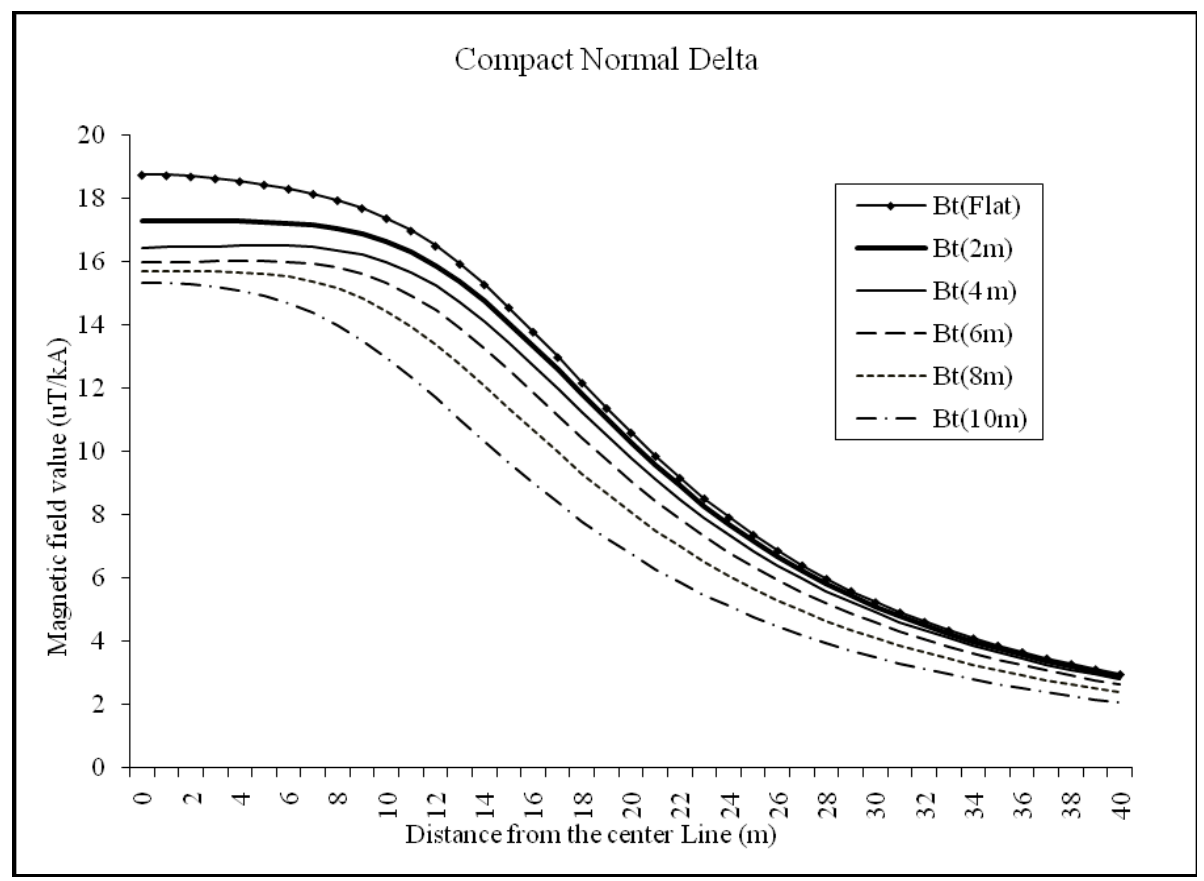

Fig. (15). Magnetic field values (uT/kA) for $500 \mathrm{kV}$ Power line with Compact normal delta and shifting up the central phase conductors, with $2 \mathrm{~m}$ steps, and keeping a constant safe distance of $13.2 \mathrm{~m}$ from the outer two phases of the power line.

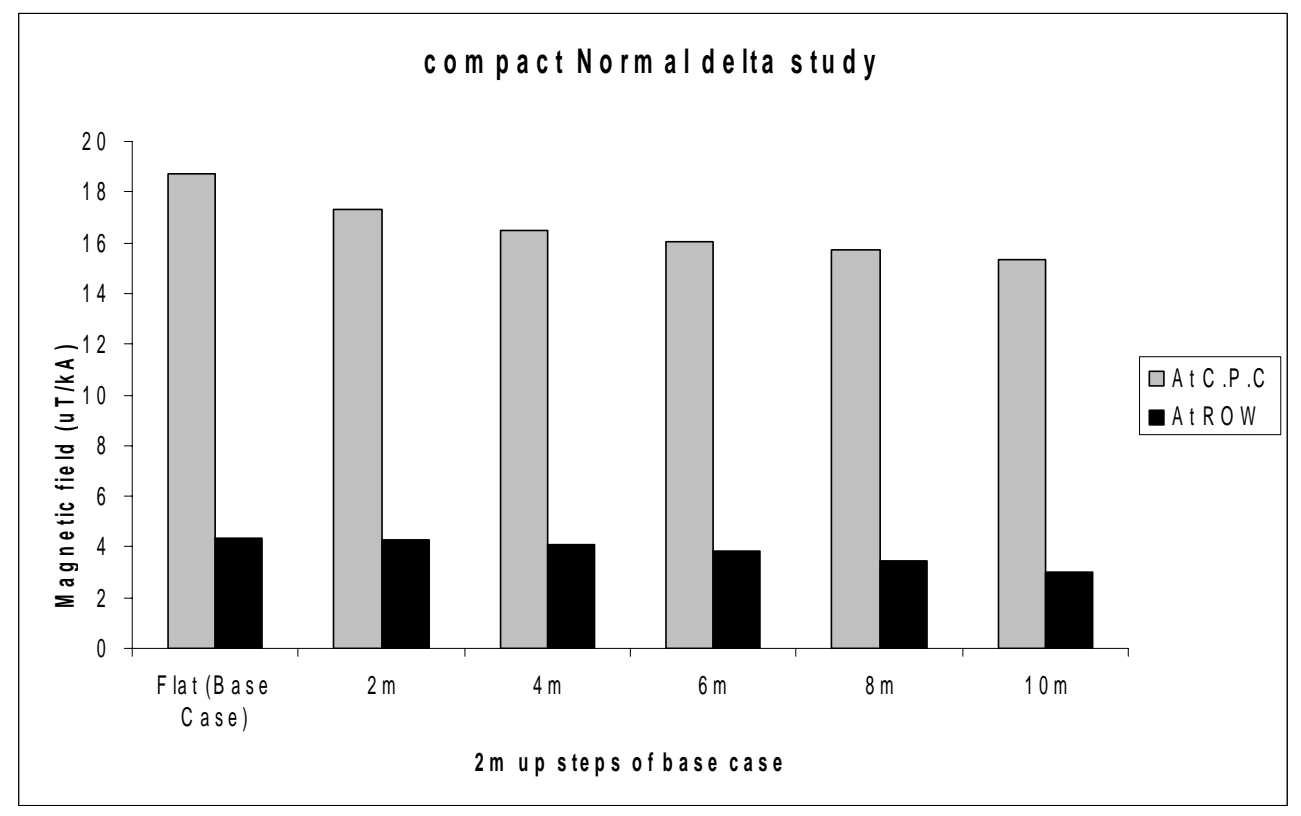

Fig. (16). The maximum magnetic field (B) values at C.P.C. and at ROW for, Compact normal delta and compared with the field value, of the Base Case.

higher than those of the conventional configuration (Conv.Delta) beyond this distance. While the resultant magnetic field values of the full compact delta configuration (D) are the lowest.

Table 7 shows the magnetic field components and total values at different lateral distances, from the central line positions of the power transmission line, with normal conventional configuration.
From Table 7, Table 8 and Fig. (13), it can be seen that, for the full compact inverted delta configuration (Inv.Delta), compared with the conventional flat case, there is a reduction of the magnetic field values, in the area covering the distance from under the central phase conductor (CPC) position up to the ROW position. The average of this reduction in the magnetic field values is around $14.6 \%$. There is an increase of the magnetic field values beyond the ROW position, com- 
pared with that of the normal conventional flat case with an average of around $7.3 \%$.

The result of the reduction of the produced magnetic fields, in the case of full compaction case, as can be seen from Table 8 compared with those of Table 7, will result in obtaining a big saving of the land around the power transmission line.

It can be seen from Table 7, Table 9 and Fig. (17) that, the resultant magnetic fields produced with the full compact inverted delta configuration, are lower than those produced from the conventional flat line configuration, with a reduction of around $31.9 \%$. Also, from a comparison of the results on Tables 7 and 9, it can be noticed that, the maximum produced magnetic field value at the ROW position, (at $25 \mathrm{~m}$ from the center line), for the case of the normal conventional flat line, is $7.492 \mathrm{uT} / \mathrm{KA}$. This value is obtained at a distance of (between $15 \mathrm{~m}$ and $16 \mathrm{~m}$ ), for the case of full compaction inverted delta configuration, with a reduction of around 36 $\%$.

This means that, there is a big saving of the land around and along the transmission line, which can be obtained by using the full compaction delta configuration.

\section{CONCLUSIONS}

From the results obtained for the different cases of studies, the following conclusions are obtained:

1) - For inverted delta configurations, the maximum magnetic field value are obtained, with the outer two phases are at the height level of $32 \mathrm{~m}$ and $34 \mathrm{~m}$ from the ground. While the positions of the maximum values, for all the considered cases remain directly, under the central phase conductors.

2) - For normal delta configuration, the maximum (B) values varies and the higher value is obtained at the case of flat configuration. With any shift up, of the central phase conductors, will increase the effects of the field cancellation factors and then reduced the maximum values.

3) - For compact inverted delta configuration (with shifting up the outer phases conductors with keeping them moving on circle curve), as higher outer phases conductors from the ground, the higher of the magnetic field (B) values are obtained under the central line.

4) - For compact normal delta configuration (with shifting up the central phase conductor and moving the outer phases horizontally at a constant height), as higher central phase conductors the lower and a reduction of the magnetic field values. With a reduction of around $31 \%$, at the ROW is obtained.

5) - For full compact inverted delta configuration (Inv.Delta), (with constant safe distance between the three phases), compared with the conventional flat case, there is a reduction of the magnetic field values, in the area covering the distance from the under the central phase conductor (CPC) position up to the ROW position. The average of this reduction in the magnetic field values is around of $14.6 \%$.

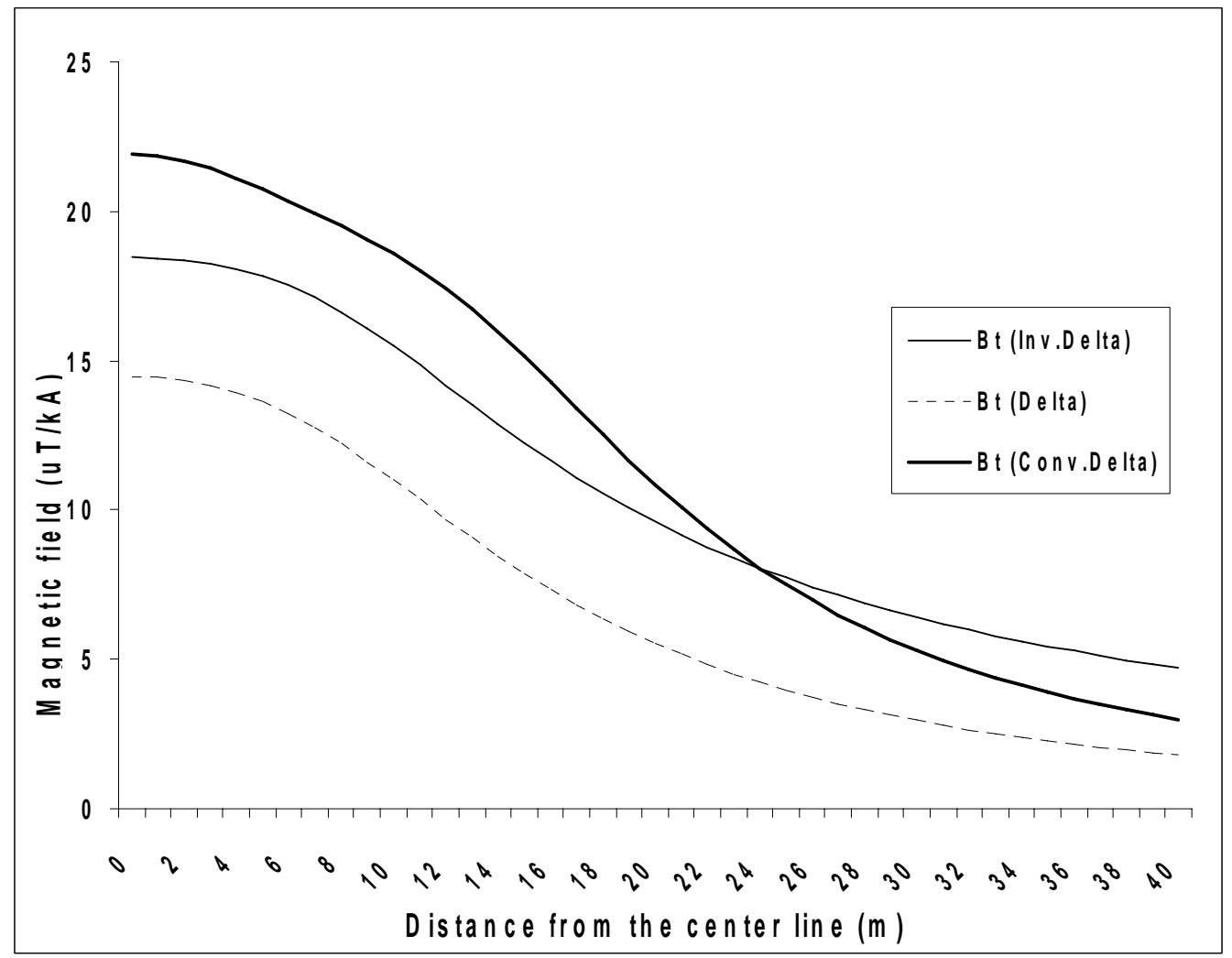

Fig. (17). The magnetic field profiles, at the mid-span of the transmission line, for full compaction normal delta (Delta), full compaction inverted delta (Inv.Delta) and the conventional configurations(Conv.Delta). 
Table 7. Magnetic fields Results Obtained at Different Distances from the Central Line, at the Mid-Span, for the Conventional Configuration with 13.2 m Space Between All Phases

\begin{tabular}{|c|c|c|c|c|}
\hline $\begin{array}{l}\text { Distance from the Central } \\
\text { Line }\left(x_{\text {m }}\right)\end{array}$ & $\begin{array}{c}\text { (bx) } \\
\text { Component } \\
(\mathbf{u T} / \mathbf{k A})\end{array}$ & $\begin{array}{l}\text { (by) } \\
\text { Component } \\
(\mathbf{u T} / \mathbf{k A})\end{array}$ & $\begin{array}{c}\text { (bz) } \\
\text { Component } \\
(\mathbf{u T} / \mathbf{k A})\end{array}$ & $\begin{array}{c}\text { The Total Magnetic Field (bt) } \\
(\text { uT/kA) } \\
\text { (Conv. Delta) }\end{array}$ \\
\hline 0 & 15.595 & 15.403 & 0.002 & 21.919 \\
\hline 2 & 14.475 & 16.156 & 0.002 & 21.691 \\
\hline 4 & 11.950 & 17.402 & 0.002 & 21.110 \\
\hline 6 & 9.929 & 17.774 & 0.002 & 20.359 \\
\hline 8 & 9.952 & 16.805 & 0.002 & 19.531 \\
\hline 10 & 11.547 & 14.555 & 0.002 & 18.579 \\
\hline 12 & 13.193 & 11.349 & 0.002 & 17.403 \\
\hline 14 & 13.916 & 7.792 & 0.002 & 15.949 \\
\hline 16 & 13.48 & 4.703 & 0.002 & 14.276 \\
\hline 18 & 12.173 & 2.968 & 0.002 & 12.53 \\
\hline 20 & 10.469 & 2.880 & 0.001 & 10.858 \\
\hline 22 & 8.744 & 3.329 & 0.001 & 9.357 \\
\hline 24 & 7.200 & 3.627 & 0.001 & 8.062 \\
\hline 25 & 6.520 & 3.690 & 0.001 & 7.492 \\
\hline 26 & 5.903 & 3.706 & 0.001 & 6.970 \\
\hline 28 & 4.848 & 3.634 & 0.001 & 6.059 \\
\hline 30 & 4.002 & 3.474 & 0.001 & 5.300 \\
\hline 32 & 3.327 & 3.272 & 0.001 & 4.666 \\
\hline 34 & 2.786 & 3.055 & 0.001 & 4.135 \\
\hline 36 & 2.352 & 2.839 & 0.001 & 3.687 \\
\hline 38 & 2.000 & 2.633 & 0.001 & 3.306 \\
\hline 40 & 1.713 & 2.439 & 0.001 & 2.981 \\
\hline
\end{tabular}

+ROW distant considered $=25 \mathrm{~m}$ from the central line.

Table 8. Magnetic Fields Results Obtained at Different Distance from the Central Line, at the Mid-Span, for the Full Compact Inverted Delta Configuration with 13.2 m Space Between all Phases

\begin{tabular}{|c|c|c|c|c|}
\hline $\begin{array}{l}\text { Distance from the } \\
\text { Central Line } \\
(\text { (x m) }\end{array}$ & $\begin{array}{c}\text { (bx) } \\
\text { Component } \\
(\mathbf{u T} / \mathbf{k A})\end{array}$ & $\begin{array}{c}\text { (by) } \\
\text { Component } \\
(\text { uT/kA) }\end{array}$ & $\begin{array}{c}(\text { bz) } \\
\text { Component } \\
(\mathbf{u T} / \mathbf{k A})\end{array}$ & $\begin{array}{l}\text { The Total Magnetic Field } \\
\text { (bt) } \\
\text { (uT/kA) } \\
\text { (Inv. Delta) }\end{array}$ \\
\hline 0 & 12.375 & 13.695 & 0.001 & 18.458 \\
\hline 2 & 12.891 & 13.097 & 0.001 & 18.377 \\
\hline 6 & 14.811 & 9.372 & 0.001 & 17.527 \\
\hline 8 & 14.728 & 7.738 & 0.001 & 16.637 \\
\hline 10 & 13.679 & 7.245 & 0.001 & 15.479 \\
\hline
\end{tabular}


Table 8. contd....

\begin{tabular}{|c|c|c|c|c|}
\hline $\begin{array}{l}\text { Distance from the } \\
\text { Central Line } \\
\text { (x m) }\end{array}$ & $\begin{array}{c}(\mathbf{b x}) \\
\text { Component } \\
(\mathbf{u T} / \mathbf{k A})\end{array}$ & $\begin{array}{c}\text { (by) } \\
\text { Component } \\
(\mathbf{u T} / \mathbf{k A})\end{array}$ & $\begin{array}{c}\text { (bz) } \\
\text { Component } \\
(\text { uT/kA) }\end{array}$ & $\begin{array}{c}\text { The Total Magnetic Field } \\
\text { (bt) } \\
\text { (uT/kA) } \\
\text { (Inv. Delta) }\end{array}$ \\
\hline 12 & 12.008 & 7.544 & 0.002 & 14.182 \\
\hline 14 & 10.141 & 7.935 & 0.002 & 12.877 \\
\hline 18 & 6.842 & 8.044 & 0.002 & 10.560 \\
\hline 20 & 5.572 & 7.817 & 0.002 & 9.600 \\
\hline 22 & 4.543 & 7.497 & 0.002 & 8.767 \\
\hline 24 & 3.716 & 7.136 & 0.002 & 8.046 \\
\hline 28 & 2.516 & 6.4 & 0.002 & 6.877 \\
\hline 30 & 2.081 & 6.053 & 0.002 & 6.400 \\
\hline 32 & 1.726 & 5.726 & 0.002 & 5.981 \\
\hline 34 & 1.435 & 5.423 & 0.003 & 5.609 \\
\hline 36 & 1.194 & 5.141 & 0.003 & 5.278 \\
\hline 38 & 0.994 & 4.881 & 0.003 & 4.981 \\
\hline 40 & 0.828 & 4.641 & 0.003 & 4.714 \\
\hline
\end{tabular}

+ROW distant considered $=25 \mathrm{~m}$ from the central line.

Table 9. Magnetic Fields Results Obtained at Different Distance from the Central Line, at the Mid-Span, for the Full Compact Delta Configuration with $13.2 \mathrm{~m}$ Space Between all Phases

\begin{tabular}{|c|c|c|c|c|}
\hline $\begin{array}{c}\text { Distance from the Central } \\
\text { Line (x m) }\end{array}$ & $\begin{array}{c}(\mathbf{b x}) \\
\text { Component } \\
(\mathbf{u T} / \mathbf{k A})\end{array}$ & $\begin{array}{c}\text { (by) } \\
\text { Component } \\
(\mathbf{u T} / \mathbf{k})\end{array}$ & $\begin{array}{c}\text { (bz) } \\
\text { Component } \\
(\mathbf{u T} / \mathbf{k A})\end{array}$ & $\begin{array}{c}\text { The Total Magnetic Field (bt) (uT/kA) } \\
\text { (Delta) }\end{array}$ \\
\hline \hline 0 & 4.528 & 13.739 & 0.001 & 14.466 \\
\hline 2 & 5.851 & 13.091 & 0.001 & 14.339 \\
\hline 4 & 8.203 & 11.268 & 0.001 & 13.224 \\
\hline 6 & 9.972 & 8.685 & 0.001 & 12.212 \\
\hline 8 & 10.579 & 6.101 & 0.001 & 10.991 \\
\hline 10 & 10.070 & 4.406 & 0.001 & 9.699 \\
\hline 12 & 8.860 & 3.946 & 0.001 & 8.455 \\
\hline 14 & 7.412 & 4.069 & 0.001 & 7.332 \\
\hline 16 & 6.035 & 4.164 & 0.001 & 6.355 \\
\hline 20 & 4.867 & 4.086 & 0.001 & 5.524 \\
\hline
\end{tabular}


Table 9. contd....

\begin{tabular}{|c|c|c|c|c|}
\hline $\begin{array}{c}\text { Distance from the Central } \\
\text { Line (x m) }\end{array}$ & $\begin{array}{c}\text { (bx) } \\
\text { Component } \\
(\mathbf{u T} / \mathbf{k A})\end{array}$ & $\begin{array}{c}\text { (by) } \\
\text { Component } \\
(\mathbf{u T} / \mathbf{k A})\end{array}$ & $\begin{array}{c}\text { (bz) } \\
\text { Component } \\
(\mathbf{u T} / \mathbf{k A})\end{array}$ & $\begin{array}{c}\text { The Total Magnetic Field (bt) (uT/kA) } \\
\text { (Delta) }\end{array}$ \\
\hline \hline 25 & 2.450 & 3.127 & 0.001 & 3.972 \\
\hline 26 & 2.257 & 2.975 & 0.001 & 3.734 \\
\hline 28 & 1.939 & 2.687 & 0.001 & 2.956 \\
\hline 30 & 1.692 & 2.423 & 0.001 & 2.650 \\
\hline 32 & 1.498 & 2.187 & 0.001 & 2.388 \\
\hline 34 & 1.341 & 1.976 & 0.001 & 2.161 \\
\hline 38 & 1.212 & 1.789 & 0.001 & 1.963 \\
\hline 40 & 1.104 & 1.624 & 0.001 & 1.791 \\
\hline
\end{tabular}

+ ROW distant considered $=25 \mathrm{~m}$ from the central line.

So, a saving of the land around the power transmission line can be obtained.

6) - For full compact normal delta configuration, (with constant safe distance between the three phases), the resultant magnetic fields produced with the full compact inverted delta configuration, are lower than that produced from the conventional flat line configuration, with a reduction of around $31.9 \%$.

This means that, there is a big saving of the land around and along the transmission line, which can be obtained by using the full compaction delta configuration.

\section{REFERENCES}

[1] S. A. Mahmoud, "Modeling and assessment of power frequency magnetic fields", Ph. D. thesis, Faculty of Engineering, Cairo University: Cairo, Egypt, 1995.

[2] M.L. Hiles, R.G. Olsen, K.C. Holte, D.R. Jensen, and K.L. Griffing, "Power Frequency Magnetic Field Management Using a Combination of Active and Passive Shielding Technology", IEEE Transactions on Power Delivery, vol. 13(1), pp.171-179, Jan. 1998.

[3] A.S. Fraag, A. Al-Shehri, J.M. Bakhashwain, T.C. Cheng, and D. Penn, " Impact of electromagnetic field management on the design of $500 \mathrm{kV}$ transmission lines", Electric Power System Research, vol. 40, pp. 203-238, 1997.

[4] A.S. Fraag, J.M. Bakhashwain, A. Al-Shehri, T.C. Cheng, and Y. Gao, "Bundled conductor configuration optimization for compact transmission lines incorporating electromagnetic fields management", Electric Power System Research, vol. 44, pp. 189-202, 1998.

[5] L. Yafang, Y. Yichao, and W. Huiren, "Study of $500 \mathrm{kV}$ compact transmission technology", Cigre 1998 conference, 1998, paper22L33L36-11, pp. 141-147.

[6] O.B.C. Miguel, C.A. Melo Luiz Fonseca, E. Fontans, and S.R. Naidu, "Electric and magnetic fields of compact transmission lines", IEEE Transactions on Power Delivery, vol. 14(1), pp. 200204, Jan 1999.

[7] P. Villa, A. Bertazzi, and M. Leva, "Compact transmission line with inverted delta configuration", Cigre 2002 conference, 2002, Paper- 22-103, pp.1-4.

[8] D. Tsanakas, "Compact and optimum phase conductor arrangement for the reduction of electric and magnetic fields of overhead lines", Cigre 2000 conference, Parise, 2000, Paper 36-103.
[9] M. Ding-zhong, "Recommendation of HVDC transmission/interconnection for every strengthened regional grids, avoiding countrywide $1000 \mathrm{kV}$ interconnection", Electric Power Automation Equipment, vol. 27(5), pp. 19-28, May 2007.

[10] C. Xu-zheng, L. Xi-dong, Z. Rong, and D. Xin-zhou, "Analysis on electric parameter characteristics of compact transmission lines in China", Power System Technology, vol. 31(1), pp. 16-19, 24, Jan. 2007.

[11] H. Dao-chun, R. Jiang-jun, W. Wu, L. Hao-xing, Z. Quan-jiang, and Z. Wei, "Study on electromagnetic environment of UHV AC transmission lines", Power System Technology, vol. 31(1), pp. 611, Jan. 2007.

[12] G. Zhi-hong, S. Wei-min, G. Bo, Y. Jin-xia, and Z. Zhen-hua, "A study on restriction of secondary arc current and time coordination of single phase reclosing for $500 \mathrm{kV}$ compact transmission line from Yuncheng to Tai'an", Power System Technology, vol. 30(17), pp. 79-83, Sep 2006

[13] P. Jing, Y. Hui, and C. Baichao, "Current situation and prospect of compact line and double circuit on same tower in China", High Voltage Engineering, vol. 31(9), pp. 25-27, Sep 2005.

[14] S. Fang-yin, "Phase conductor configuration and power frequency electromagnetic environment of UHV transmission lines in China", Power System Technology, vol. 29(8), pp. 1-7, Apr 2005.

[15] Y. You-wen, and J. Yong-chun, "Key technologies for $500 \mathrm{kV}$ compact transmission line from Changping to Fangshan", Power System Technology, vol. 27(7), pp. 75-77, July 2003.

[16] S. Yin-biao, and Z. Cheng-hua, "Study and implementation of 500 $\mathrm{kV}$ compact power transmission line with double circuits on a same tower in China", Power System Technology, vol. 26(4), pp. 49-51, Apr 2002.

[17] C. Boylan, "Testing and installation of a $110 \mathrm{kV}$ compact line", UPEC 2000. 35th Universities' Power Engineering Conference, (UPEC 2000), Belfast, UK, 6-8 September 2000, pp. 1-5.

[18] H. Olsson, P. Pettersson, and A. Eriksson, "Reduction of transmission line magnetic fields-possibilities and constraints", Cigre 1990 conference, Paris, 1990, Paper 36-101.

[19] C.J. Durkin, R.P. Fogarty, T.M. Halleran, D.A. Mark, and A. Mukhopadhyay, "Five years of magnetic field management", IEEE Transactions on Power Delivery, vol. 10, No. 1, pp. 219-228, Jan 1995.

[20] A. T. Wilson, P. J. Wallace, and D. C. Smith, "Magnetic field effects in the victoria transmission system - design and measurement", Cigre 1990 conference, Paris, 1990, Paper 63-103.

[21] Electrical Power Res Institute (EPRI), "Transmission line reference book, $345 \mathrm{KV}$ and Above", The Red Book, $4^{\text {th }}$ ed. USA: General Electric Co., 2001. 
[22] Electrical Power Research Institute (EPRI), "AC transmission line reference book, $200 \mathrm{KV}$ and Above", $3^{\text {rd }}$ ed. USA: General Electric Co., 2005.

[23] Electrical Power Research Institute (EPRI), "Transmission line reference book, 115-345- KV compact line design", The Blue Book, USA: General Electric Co., 2008.

[24] H. Anis, M.A. Abd-Allah, and S. A. Mahmoud, "Computation of power line magnetic fields - a three dimensional approach", $9^{\text {th }} I n$ ternational symposium on high voltage engineering (ISH 1995), Graz Austria, Aug/Sept 1995, paper 8333.

[25] K. Isaka, N. Hayashi, and Y. Yokoi, "Characterisation of electrical and magnetic fields at ground level under EHV transmission lines",
International Symposium on High voltage Engineering, 26-30 Aug 1991.

[26] A-S.H. Hamza, S.A. Mohmoud, and S.M. Ghania, "Environmental pollution by magnetic field associated with power transmission lines", Energy Conversion and Management, vol. 43, pp. 24432452, Nov 2002

[27] A-S.H. Hamza, "Evaluation and measurement of magnetic field exposure over human body near EHV transmission lines", Electric Power Systems Research, vol. 74, pp. 105-118, 2005.

(C) Nagat Mohamed Kamel Abdel-Gawad; Licensee Bentham Open.

This is an open access article licensed under the terms of the Creative Commons Attribution Non-Commercial License (http://creativecommons.org/licenses/by-nc/3.0/) which permits unrestricted, non-commercial use, distribution and reproduction in any medium, provided the work is properly cited. 